\title{
EL USO DEL CONCEPTO CÁNCER COMO METÁFORA SOCIAL. ANÁLISIS A TRAVÉS DE LA PRENSA ESCRITA (1903-1912)
}

\author{
The Use of the Concept of Cancer as a Social Metaphor: \\ Analysis through the Written Press (1903-1912) \\ Laura Almudéver Campo y Ramón Camaño Puig ${ }^{1}$ \\ Universitat de València \\ laura.almudever@uv.es-ramon.camano@uv.es
}

\section{Resumen}

El objetivo de este artículo es analizar el uso del término cáncer desde una perspectiva social y su representación en la prensa española a comienzos del siglo xx (1903-1912), en los periódicos La Vanguardia y $A B C$. A partir de la hemeroteca digital de ambos medios se seleccionaron todas y cada una de las veces que se pudo identificar el término «cáncer» y su aplicación metafórica desde una perspectiva de problemática social, procediéndose a la descripción de los rasgos significativos y al análisis del discurso. Encontramos un uso de la palabra cáncer como metáfora social a lo largo del periodo estudiado, siendo común extender la metáfora del cuerpo enfermo a situaciones de orden político o social. El cáncer es una enfermedad con un gran impacto en nuestra sociedad, cuya utilización metafórica es descriptiva y expresa el deseo del cambio, pero

1 Laura Almudéver Campo es doctora en Enfermería por la Universidad de Valencia (2016), máster en Enfermería Oncológica (2011) y licenciada en Periodismo (2007). Compagina su labor asistencial con la docencia, como profesora asociada en la Facultad de Enfermería de la Universidad de Valencia. ORCID ID: https://orcid.org/0000-00023049-4879. Ramón Camaño Puig es doctor europeo (1997) por Leeds Metropolitan University (UK), enfermero y licenciado en Comunicación Audiovisual por la Universidad de Valencia. Actualmente trabaja como profesor titular en la Universidad de Valencia. ORCID ID: https://orcid.org/0000-0002-8018-2232. 
su empleo puede comportar la estigmatización de los enfermos afectados por esta patología.

Palabras clave: cáncer, metáfora, sociedad, prensa, España.

\section{Abstract}

The objective of this article is to analyze the use of the term cancer from a social perspective and its representation in the Spanish press at the beginning of the $20^{\text {th }}$ Century (1903-1912), in the newspapers La Vanguardia and ABC. From the digital mass media library, each and every one of the times that the term «cancer» and its metaphorical application could be identified from a perspective of the social problem was selected, proceeding to the description of the essential features and the discourse analysis. A use of the word cancer as a social metaphor was found throughout the studied period, being common to extend the metaphor of the sick body in situations of political or social order. Cancer is a disease with a great impact on our society, metaphorical use is descriptive and expresses the desire for change, but its use may involve the stigmatization of patients affected by this pathology.

Key words: cancer, metaphor, society, press, Spain.

\section{INTRODUCCIÓN}

Los seres humanos nos comunicamos a diario haciendo uso del lenguaje de manera casi automática e introduciendo elementos metafóricos, lo que según las teorías cognitivas se consideran expresiones de metáforas conceptuales construidas a nivel del pensamiento. ${ }^{2}$ Algunas metáforas pueden ser comunes a diferentes culturas y lenguas pero su estructuración y expresión lingüística pueden estar modificadas en mayor o menor grado, pudiéndose extender fácilmente al lenguaje cotidiano, pues expresan «conceptualizaciones semánticas ricas y poseen un enorme poder evocativo de imágenes vividas y un indispensable poder explicativo y comunicativo». ${ }^{3}$

2 Lakoff, G., Johnson, M., 1981, Metaphors We Live By. Chicago, The University of Chicago Press; Lakoff, G., 1993, «The Contemporary Theory of Metaphor». En Orton y Andrew, editors. Metaphor and Thought. Cambridge, Cambridge University Press, 202-251; Gibbs, R., 1994, The Poetics of the Mind. Figurative Thought, Language, and Understanding. Cambridge, Cambridge University Press.

3 Gibbs, R., 1994, The Poetics of the Mind. Figurative Thought, Language, and Understanding. Cambridge, Cambridge University Press. 
La metáfora es definida por el diccionario de María Moliner ${ }^{4}$ como «tropo que consiste en usar palabras con sentido distinto del que tienen propiamente, pero que guarda con éste una relación descubierta por la imaginación». Algo que ocurre en la denominación de distintas enfermedades, que son utilizadas de manera regular para representar aspectos de disfuncionalidad en el ámbito de lo social, en donde la elección de la enfermedad responde a los criterios de aquellos que las utilizan y habitualmente representan de manera esquemática las ideas de su autor. Por tanto, puede ser utilizada cualquier enfermedad de la que no se tenga claro su mecanismo de producción y comporte peligro, descomposición, polución, debilidad, etc., a lo que se puede sumar la existencia de tratamientos más o menos inefectivos.

La enfermedad es habitualmente recubierta de una patina de significados que usualmente contienen elementos morales y didácticos que pretenden disciplinar a la vez que corregir. La aplicación del nombre de la enfermedad a cualquier otro proceso, en términos de metáfora, impone todas las características descritas y atribuidas a las enfermedades, adjetivando el proceso. Todo aquello que denominemos como la enfermedad se convierte, por tanto, en sórdido, horrible y repulsivo.

En nuestro caso, el cáncer, cuya denominación se atribuye a Hipócrates (460-370 a.C.), utilizó los términos griegos karkinos y karkinoma para describir tumores ulcerativos y no ulcerativos. En latín, cáncer significa cangrejo. Tal como señala Sontag ${ }^{5}$ «la definición literal más antigua de cáncer es la de una excrecencia, chichón o protuberancia», lo cual de acuerdo con Galeno (130-210 d.C.) establece el parecido entre las venas hinchadas de un tumor exterior y las patas de un cangrejo.

La palabra cáncer nos trasmite una serie de connotaciones de rápida aprehensión, entre las que podemos extraer la dificultad para proceder a la erradicación del mal y su persistencia, enfermedad de carácter abrupto, con rápido y desmesurado crecimiento y que afecta a la víctima con dolor. Una enfermedad que roe, devora y consume, lo que se relaciona con la categoría de gangrena que a su vez se asocia con la propia enfermedad, muerte y putrefacción, nociones que permanecen a lo largo del tiempo y perduran también hasta la actualidad.

4 Moliner, M., 1998, Diccionario de uso del español. Madrid, Gredos, sub voce.

5 Sontag, S.,1990, Illness as metaphor and aids and its metaphors. New York, Double day Books. 
Sontag (1990) afirma que una de las características por las que se utiliza el cáncer como metáfora, en sus diferentes tipos, entre ellos el social, es su origen desconocido. La propia Real Academia la incluye entre sus acepciones desde 2001, como: "proliferación en el seno de un grupo social de situaciones o hechos destructivos» y da como ejemplo: «La droga es el cáncer de nuestra sociedad». 6

La utilización de esta metáfora en el ámbito social demanda la utilización de tratamientos agresivos en términos de alcanzar la curación y lograr, de esta manera, el restablecimiento de la salud y, por tanto, del orden. Cuando el organismo se ha visto afectado por la enfermedad, no cabe la utilización de medidas de contención, es indispensable la utilización de medidas de erradicación, eliminando los elementos enfermos y propiciando un nuevo comienzo.

Los medios de comunicación suelen incluir metáforas para informar y reducir la incertidumbre en la audiencia acerca de las temáticas que pueden desconocer. Las noticias tienen que impactar con algo familiar y conectado con formas previas de encuadres noticiosos, a través de diferentes temáticas $^{7}$. En este proceso, las metáforas ofrecen una forma de comprensión de procesos complejos y nuevos contenidos en términos de experiencias compartidas y las usan con la intención de popularizar, dramatizar y concretar las temáticas; en resumen, para obtener que los temas sean importantes para la audiencia ${ }^{8}$ o también, tal y como Bucchi ${ }^{9}$ pone de manifiesto, «para dirigirse a diferentes audiencias de manera simultánea».

En este artículo pretendemos analizar cómo el lenguaje y las metáforas fueron utilizadas en dos medios de comunicación escrita en nuestro país a comienzos del siglo xx, lo que nos ofrece, en un momento en el que los conocimientos acerca del cáncer eran bastante escasos, un marco analítico acerca de un extenso conjunto de interpretaciones que se han llevado a cabo en torno al concepto de cáncer y su aplicación de manera metafórica a los problemas sociales. Intentaremos proporcionar explicaciones acerca

6 Instituto de Investigación Rafael Lapesa, 2013, Real Academia Española. Mapa de diccionarios académicos. Disponible en: <http://web.frl.es/ntllet>

7 Gamson, W. y Modigliani, A., 1989, «Media discourse and public opinion on nuclear power: a constructionist approach». American fournal of Sociology, 95 (1), 1-37. <https:// doi.org/10.1086/22921310.1086/229213>

8 Anton, T.y McCourt, R., 1995, The new science journalist. New York, Ballantine Books.

9 Bucchi, M., 1998, Science and the media: Alternative routes in science communication. London, Routledge. 
de su vigencia en relación con las preocupaciones políticas, la cultura de los medios, y responder a cuestiones tales como a qué se hacía alusión cuando se hablaba de cáncer desde una perspectiva social y cómo era representada en el sentido social en los medios de comunicación de la época. Intentaremos constatar la existencia de lugares comunes respecto de los pacientes, relacionados con épocas precedentes y si éstos podrían reconocerse en su posible proyección a la actualidad; todo ello a partir, en lo posible, del reconocimiento de las metáforas utilizadas en las que se hacía referencia al cáncer.

\section{MÉTOdo}

Todo trabajo de investigación supone un primer paso de análisis de la literatura existente sobre la temática elegida, así como aquellos aspectos que se acercan a la investigación propuesta (la selección, el análisis, el estudio de los documentos y las publicaciones). A partir de aquí, establecimos una serie de criterios para la selección de las publicaciones analizadas que se han basado en la elección de dos diarios de información general de mayor difusión en el ámbito geográfico del estado español, desde el 1 de enero de 1903 hasta el 31 de diciembre de 1912.

Los periódicos seleccionados para el estudio fueron $A B C$ y La Vanguardia. De ideología aparentemente distinta, eran representativos de las dos ciudades españolas más importantes, como fueron Madrid y Barcelona respectivamente, con lo que conformaban una parte esencial del nuevo periodismo español. Podríamos considerar que ambos periódicos contribuyeron de una manera u otra a la creación de la metáfora del cáncer atribuible a problemas sociales.

Fueron consultados en su versión digital, a través de la hemeroteca digital de los propios medios, donde se procedió, por tanto, a seleccionar todas y cada una de las veces en las que se utilizó la palabra «cáncer», como muestra para el análisis y discernir su aplicación metafórica desde una perspectiva de problemática social.

Para analizar los contenidos hemos utilizado la definición de Berelson ${ }^{10}$ de 'análisis de contenido': "Descripción cuantitativa, objetiva y sistemática del contenido manifiesto de la comunicación» y se propuso la crea-

10 Berelson, B., 1952, Content analysis in communication research. New York, Free Press. 
ción de una serie de códigos que mostraran el contenido de los textos y las situaciones reflejadas, lo que nos condujo a la siguiente fase: tratar de hacer hablar a los datos contenidos en los artículos periodísticos a través de procedimientos de reducción en términos de selección y condensación de los mismos, exponerlos, sacar y verificar conclusiones, mediante un proceso de descomposición de los datos en sus elementos constituyentes para revelar sus temas y patrones característicos ${ }^{11}$.

Los artículos periodísticos realizados por diferentes periodistas comportaron la disolución de los acontecimientos en multitud de detalles específicos, describiendo una realidad que se presentaba solo como texto ${ }^{12}$. En este sentido, se han codificado las expresiones en las que se utilizó la palabra cáncer en términos sociales y que fueron trasmitidas por escrito en los periódicos. A lo largo del proceso, se han ido confeccionando memorandos para seguir los pasos que se han dado durante la investigación y ayudar a la propia reflexión para que contribuyera al proceso de codificación y categorización.

\section{Resultados}

El periódico $A B C$ Madrid se publicó a lo largo de los años 1903, 1904 y 1905 de manera irregular. Desde el primer día de la publicación de este periódico, es decir, desde el 1 de enero de 1903, hasta el 31 de diciembre de 1905, la periodicidad en su publicación era variable, publicándose en estos años un total de 353 días. Los siguientes años analizados, desde 1906 a 1912 inclusive, la periodicidad del periódico era diaria, lo que significa que se publicó 363 periódicos por año, es decir, 2.541 veces. Esta cifra, sumada a la de los años anteriores $(1903,1904$ y 1905), hace un total de 2.894 periódicos analizados. Para nuestro estudio, además de analizar la edición ABC Madrid, también incluimos la publicación semanal del suplemento Blanco y Negro, que se publicaba semanalmente. De esta manera, se obtuvieron 52 publicaciones por año, que multiplicado por los diez años de nuestro estudio hizo un total de 520 suplementos. Esta cifra, sumada a la de $A B C$ Madrid da un total de 3.414 ediciones analizadas.

11 Coffey, A., Atkinson, P., 2003, Encontrar el sentido a los datos cualitativos: estrategias complementarias de investigación. Medellín, Editorial Universidad de Antioquia.

12 Fiske, J., 1991, "The discourses of TV quiz shows, or school + luck = success + sex». En: L. R. Vande Berg y L. A. Wenner, editors. Television criticism: Approaches and Applications. White Plains, NY, Longman, 445-462. 
Por su parte, el periódico La Vanguardia fue publicado 363 veces por año, sin ninguna limitación temporal, y el número de periódicos analizados ha sido de 3.630 , lo que, sumado a los 3.414 números analizados del $A B C$, hace un total de 7.044 .

Una vez obtenida la muestra de estudio, se seleccionaron todas aquellas publicaciones en las que apareciera publicado el concepto cáncer. Como se muestra en la Tabla 1, el número de publicaciones en el periódico $A B C$ fue de 411, mientras que en La Vanguardia fue de 272, obteniendo un total de 683 unidades de análisis.

Tabla I. Número de publicaciones en cuyo contenido aparece el término cáncer.

\begin{tabular}{|l|c|c|}
\hline & $\begin{array}{c}\text { RELATIVO A LA } \\
\text { ENFERMEDAD }\end{array}$ & $\begin{array}{c}\text { RELATIVO A LO } \\
\text { SOCIAL }\end{array}$ \\
\hline ABC & $411\left(60^{\prime} 17 \%\right)$ & $16(3,89 \%)$ \\
\hline LA VANGUARDIA & $272\left(39^{\prime} 83 \%\right)$ & $18(6,61 \%)$ \\
\hline TOTAL & $683(100 \%)$ & $34(4,97 \%)$ \\
\hline
\end{tabular}

Elaboración propia a partir de los diarios seleccionados.

En el periódico $A B C$ y en La Vanguardia encontramos un uso de la palabra cáncer como metáfora social a lo largo del periodo estudiado, apareciendo del orden de dieciséis veces $(3.89 \%)$ en el primero, y dieciocho $(6.61 \%)$ en el segundo, por lo que se podría decir que el uso de este recurso lingüístico es más o menos similar en ambos medios, apareciendo en conjunto treinta y cuatro veces $(4.97 \%)$. En la Tabla 2 se muestra la distribución según el año de publicación.

Tabla II. Distribución según año de publicación.

\begin{tabular}{|l|c|c|c|c|c|c|c|c|c|c|c|}
\hline & $\mathbf{1 9 0 3}$ & $\mathbf{1 9 0 4}$ & $\mathbf{1 9 0 5}$ & $\mathbf{1 9 0 6}$ & $\mathbf{1 9 0 7}$ & $\mathbf{1 9 0 8}$ & $\mathbf{1 9 0 9}$ & $\mathbf{1 9 1 0}$ & $\mathbf{1 9 1 1}$ & $\mathbf{1 9 1 2}$ & TOTAL \\
\hline ABC & & 1 & & 2 & 2 & & 2 & 4 & 2 & 3 & 16 \\
\hline $\begin{array}{l}\text { LA } \\
\text { VANGUARDIA }\end{array}$ & 1 & & 1 & 2 & 1 & 4 & 1 & 2 & 1 & 5 & 18 \\
\hline TOTAL & 1 & 1 & 1 & 4 & 3 & 4 & 3 & 6 & 3 & 8 & 34 \\
\hline
\end{tabular}

Elaboración propia a partir de los diarios seleccionados. 
A partir de estos datos se obtuvieron una serie de categorías que se corresponden con la tradición en el uso del concepto. Por ejemplo, en la página 2 del $A B C$ del veintiuno de julio de 1904, la mendicidad como alteración del orden: «Para extirpar de raíz el cáncer de la mendicidad, no solo en la capital»; la apariencia física de aquellos que la practican: «desnarigados por la roña del cáncer, con úlceras cruentas y perennes siempre al descubierto». En la página 9 del ejemplar del $A B C$ del veintiuno de noviembre de 1910: «los mendigos oficiales, los tullidos que le presentan al viajero el triste espectáculo de ese cáncer social». En la página cuatro del dos de julio de 1907, haciendo referencia a la utilización de la infancia y su explotación para la mendicidad como alteración del orden social: «de inocentes criaturas a la mendicidad, a la golfería y a la infancia abandonada y delincuente, cáncer social el más funesto de las grandes urbes». E incluso como una epidemia que afectaba a una gran urbe, en la página 5 de La Vanguardia del quince de agosto de 1908, con el titular «La miseria en Londres ¿Cuál es el microbio de este cáncer devastador que se llama la pobreza?»

El concepto cáncer como metáfora se utilizó también para analizar las actuaciones de los independentistas en Quebec (Canadá), un recurso que los medios de comunicación usaron en nuestro país para hacer referencia a movimientos sociales y autonomistas tales como la semana trágica de Barcelona, constituyendo una nueva categoría. Por ejemplo, en la página 1 del $A B C$ del veintiocho de abril de 1907, se pregunta acerca de los peligros del autonomismo, combatiendo la idea de España, introduciendo ideas anarquistas y si esto, no podría ser «tratar de curar el reuma inoculando el cáncer». De tal manera que en la página $6 \mathrm{del} A B C$ de cinco de septiembre de 1909 , se plantea que «el problema catalán continuará en el mismo estado, manteniéndose un cáncer en la política española». Una situación que parece que viene de lejos y hace referencia al menos a otro texto publicado el dos de enero de ese mismo año (página 5) en el que se planteaba como titular «El pleito del regionalismo» y propone como ejemplo, no emular la «exaltación del utilitarismo y el placer a únicas finalidades de la vida, de lo cual nacen los apaches como cáncer social cuyo crecimiento y hazañas no tiene la nación fuerzas para reprimir». En esencia, se trataba del desorden social, lo que supone que una parte de la sociedad no obedeciera determinadas normas manifiestamente injustas (en esos momentos se estaba reclutando a gente para la guerra de Marruecos y los pertenecientes a clases pudientes se podían librar previo pago de 1.500 pesetas).

Unos fenómenos que van a tener su impacto en el desarrollo de la semana trágica de Barcelona, tal y como se puede ver a continuación. En la 
página 9 del veintiocho de julio de 1909, se apela desde el periódico $A B C$, ante los atentados cometidos en Cataluña durante la Semana Trágica, a la falta de «Patriotismo» de los ciudadanos al negarse a ser reclutados para participar en la guerra de Marruecos exigiendo las medidas necesarias para «cauterizar pronto ese vergonzoso cáncer, esa asquerosa lacra que ante el mundo nos deshonra». Para el dieciocho de febrero de 1912, en la página once de La Vanguardia, en la sección denominada Nota política, aparece el orden del día y una reseña de los debates del Congreso en el que se demanda conocer cuándo acabará nuestra acción en el Rif, ya «que va siendo un cáncer que corroe todas las energías nacionales», en una clara alusión metafórica a los costos que la guerra está teniendo sobre los recursos del país.

Adicionalmente, otros temas son considerados desde esta perspectiva metafórica como cáncer social, por ejemplo: en la página uno de La Vanguardia del siete de noviembre de 1906, el autor de un artículo denominado «Concursos pajariles» plantea la desviación del orden que para una sociedad como la de Barcelona supone la realización de concursos de canto de pájaros con la anuencia de las autoridades, expresándose de la siguiente manera "aún quedan resabios de un cáncer que corroe las entrañas, manifestaciones casi salvajes de un espíritu que pretende negar a Barcelona el derecho de ciudad civilizada»; estableciendo como patrón de comportamiento el que este tipo de actividades serían impensables en otras ciudades europeas.

Una nueva categoría se creó a partir de la página ocho del seis de abril de 1904 de LaVanguardia, en la que encontramos en el apartado de Noticias una referencia a un viaje del Rey a Barcelona, en la que se aprovecha para establecer una confrontación de personalidades entre los catalanes y los madrileños a los que se define como «unos hombres pálidos, cuya ocupación se funda en echar cuentas galanas o en discutir, sobre el inmundo gallinero todo lo que no importa; pues lo importante tiene más amplitud que sus cabezas anémicas y sus cráneos microcéfalos» y en donde se describe Madrid como «corazón podrido [en el que] se exhala el vaho deletéreo del cáncer; la emanación morbosa que infesta las células, los tejidos, los órganos, los aparatos todos cuya función armónica produce la vida, la fecundidad y la fuerza».

En la página seis del doce de abril de 1907 de La Vanguardia bajo el titular Las lecturas, se establece un paralelismo entre el control que se lleva a cabo de todo tipo de substancias y compuestos en aras de la Salud Pública, con el descuido que se tiene a la hora de controlar la circulación de libros periódicos y otros tipos de lectura que generan males inmensos y jóvenes 
desmadrados e idiotas. El control de libros y periódicos podría restablecer el orden social y «extirpar el cáncer que corroe a la sociedad». Una situación de la que no cesa de hablarse y que volvemos a encontrar un tiempo después en la página tres de La Vanguardia, del 26 de octubre de 1908, en la que se demanda la persecución de la inmoralidad pública en sus múltiples manifestaciones de la prensa, el teatro, las artes gráficas y aún del lenguaje, contenida en ciertos momentos por el celo de la autoridad, lo cual «requiere disposiciones del poder ejecutivo o acuerdos del legislativo que permitan combatir de una manera más eficaz este cáncer social».

En la página seis de La Vanguardia del catorce de junio de 1908, encontramos una columna escrita en cursiva y con el titular Cotidianas, en una referencia a determinadas sublevaciones y comportamientos dictatoriales ocurridos en distintos países de Sudamérica, expresándose el autor en relación con estos sucedidos tal y como aparece a continuación: «El espectro repulsivo de la tiranía, la cárdena y siniestra figura de los pequeños dictadores y déspotas, destaca a nuestros ojos como cáncer de aquella sociedad naciente». Identificando a los pequeños dictadores y déspotas, con el concepto de cáncer, elemento que desde sus inicios afecta al orden necesario para que una sociedad «naciente» pueda desarrollarse adecuadamente.

En la página tres de La Vanguardia del día dos de octubre de 1908, se comunica la programación de una conferencia a celebrarse en el Paraninfo de la Universidad de Barcelona con motivo de la inauguración del curso académico 1908-09, en la que se identificaba al propio cáncer como un problema social tal y como indica el título de la conferencia del doctor Morales Pérez, denominada El cáncer como plaga social.

En la página nueve de La Vanguardia del diecisiete de abril de 1910, se analizaba la situación de nuestro país en términos de competitividad y se ponía de manifiesto la poca asiduidad a actividades de formación, determinando el periodista que: «La apatía es en nosotros, un cáncer maligno que nos aniquila paulatinamente», una referencia a la falta de competitividad del español ante otros países y por supuesto, la abulia que ante el crecimiento de éstos se percibía.

En la página siete de La Vanguardia del día veintiséis de octubre de 1910, encontramos toda una defensa de los derechos de la mujer en la que se acusa a los poderes públicos de permitir que se continúe con una «notoria injusticia, juzga a la mujer como un ser de inferior nivel a quien no debe ponerse en condiciones de que desenvuelva su actividad y su inteligencia para encontrar en el trabajo medios con que atender a su subsistencia, si en 
su camino no encuentra la mano de un hombre que noblemente la proteja contra toda clase de asechanzas, olvidando aquel que de ellas nacieron y que sus hijas por la falta de educación que reciben, pueden también un día ser un montón de carne que se ofrezca al comprador». Para terminar, utilizando el concepto cáncer como metáfora mediante la que sienta la existencia de un desorden social, en relación con las carencias educativas de las mujeres: «jamás los poderes públicos se han preocupado en forma práctica de atenuar el cáncer que corroe el social organismo».

En la página siete del $A B C$ de veinte de marzo de 1906, bajo el título San Francisco de California se hace una presentación de las beldades y la historia de la ciudad y se resalta como curiosidad la existencia de un barrio chino, al que se refiere como «un pueblo chino con la misma suciedad, con las barberías, fumaderos de opio, casas de juego, etc., un barrio chino, un verdadero cáncer en la Metrópoli norteamericana del Pacífico».

En la página cuatro de La Vanguardia del siete de marzo de 1905, se reflejan los problemas existentes respecto a la recaudación de impuestos en nuestro país. El impuesto al consumo es un impuesto de recaudación municipal, y se planteaba que: «en otros países han extirpado este cáncer de la pública administración» y se animaba a los ciudadanos y a la administración a intentar eliminarlo mediante diferentes argumentos, pero sin ofertar alternativas a cambio: «El no intentarlo nosotros acusaría imperdonable flaqueza de ánimo; el no acertar con los medios demostraría en los gobernantes torpeza inexcusable; en los gobernados, incapacidad manifiesta de gobernarse a sí mismos». En esta misma línea encontramos años más tarde referencias al impuesto al consumo, en la página nueve de La Vanguardia del ocho de marzo de 1912, en la sección Nota Política, en donde se comentaban las discusiones del Parlamento en torno a los presupuestos y la hacienda pública, llegando a la conclusión de que la falta de control y la magnitud de la suma de todas las pequeñas defraudaciones conducen a una situación de compromiso y afectación: «cuando las cosas no tienen ya remedio, se plantean elevados debates económicos, como si el origen de tantas desdichas no pudiera encontrarse en añejos errores, en tantas polacadas, en tanta voluntaria abdicación de fiscalización, en toda esa cohorte de vicios y abusos administrativos, pequeños en sí, insignificantes considerados aisladamente, pero que en conjunto son cáncer corrosivo para las energías de la nación».

En la página nueve de La Vanguardia del dos de mayo de 1912, se producen unos nuevos comentarios respecto al gobierno y el tema de los impuestos que «se hallan acometidos de un mal de difícil curación, de un 
cáncer que va royéndoles poco a poco su potencia vital». Un tema que continuó de forma reiterada en los medios y al cual se vuelven a referir en este mismo mes como un cáncer, en la página siete de La Vanguardia del veinticinco de mayo de 1912, en la sección Nota política, haciéndose mención del impuesto al consumo, en este caso, planteándose la necesidad de llevar a cabo una distribución de la carga impositiva de manera adecuada entre ricos y pobres, y que esto sirva para llevar a cabo los pagos de manera correcta y se persiga la defraudación: «Pongámonos en la triste realidad para que la llaga, ya bastante honda, no se convierta en grave cáncer; hágase justicia equitativa».

En la página cuatro del $A B C$ del ocho de marzo de 1910, procedente del corresponsal en Nueva York, bajo el titular La carestía de la vida moderna, nos encontramos claras referencias a pecados capitales tales como la avaricia y la vanidad: «La ansiedad del oro lleva a la avaricia; la saciedad del oro lleva a la vanidad. Vanidad de cuerpo, de alma y de esencia» y pretende utilizar la metáfora del cáncer a modo de advertencia: «se ve la plaga del mal más de cerca y se presiente cuan desastrosa sería la invasión de ese cáncer en el sistema social». La utilización del cáncer como metáfora en aspectos relacionados con los pecados capitales parece un recurso habitual, pues así lo encontramos en dos ocasiones más. En la página siete del $A B C$ (suplemento Blanco y Negro) del siete de julio de 1912, se publicó el relato Tejas Arriba de Vicente Díaz de Tejada, en el cual se hacía referencia a la avaricia como un cáncer, un mal que la Pepona, protagonista del relato, reconocía como un «cáncer insaciable que roía sus entrañas». Por otra parte, el veinticuatro de noviembre de 1906, en la página 19, bajo el titulo Escritores y periodistas en París aparecía una referencia a la envidia como cáncer en relación con el escritor Rubén Darío, del cual informaba que se encontraba en buenas condiciones de salud, a pesar de su carácter hipocondríaco y del que comentaba que «mañana sospechará que la envidia ajena, convertida en cáncer, le roe lentamente el corazón y le tritura el cerebro. ¡Cosas de Poeta...!»

En la página nueve del $A B C$ del día veintitrés de junio de 1910, nos encontramos una discusión parlamentaria acerca de las características de la obtención de representación parlamentaria de un tal Hoyos, el cual estaba bajo escrutinio y sobre el que había una sentencia del Tribunal Supremo. En la discusión el Sr. Moret se manifestaba de la siguiente manera: «ahora que estamos frente a ese cáncer que reclama la intervención quirúrgica», pidiendo la sanción penal y la retirada del acta parlamentaria, del tal Hoyos. En este caso, la corrupción política calificada como cáncer y necesita- 
da de acciones radicales tales como la extirpación quirúrgica. Otros ejemplos los encontramos en la página ocho del $A B C$ de veintiuno de octubre de 1910, en donde se hace una reseña del discurso del Sr. de la Cierva, en el Círculo Conservador y en donde se pone en cuestión la hipocresía con la que se actúa a nivel parlamentario en la regulación normativa equiparándola con un cáncer: «Ése es, en mi sentir, el cáncer principal que corroe nuestra vida política; se discuten las leyes y se promulgan en la Gaceta, para después ser burladas o no aplicadas por los mismos que fingieron ser sus más firmes iniciadores y defensores». En esta misma línea, en la página nueve del $A B C$ de treinta de enero de 1912, se realizó la Crónica Parlamentaria en la que se resaltaba bajo el encabezado de Pequeño incidente una discusión acerca de los jueces en donde se decía que «una pequeña parte de jueces que prevarican, por la presión del cacique, del diputado, del senador y del Gobierno. Esto es un cáncer, un mal irremediable». Un asunto que tuvo su eco también en la página siete de La Vanguardia del treinta de enero de 1912, en la sección de la Sesión del Congreso, y en la que se informaba sobre la continuación del debate acerca del dictamen de reforma del procedimiento para procesar a los senadores y diputados por razón de delito en donde después de una ardua discusión acerca de su tratamiento en el Tribunal Supremo y diferentes delitos de prevaricación y corrupción política, el Sr. Sol y Ortega planteaba: «De esto tenéis todos que confesaros, añade, es un cáncer este asunto, en nuestro país, que puede traer fatales consecuencias». Por último, en la página seis del $A B C$ del cinco de enero de 1911, bajo el epígrafe de Crónica Extranjera se presentaba el delito de desfalco como un cáncer: «El cáncer de la inmoralidad es incurable en Rusia, acaba de descubrirse un desfalco enorme, con el nombre y el prestigio de la Cruz Roja».

Otra nueva categoría se puede plantear a la hora de la utilización de la palabra cáncer haciendo referencia a dos aspectos relacionados con la descomposición de las organizaciones, una de ellas como una cuestión negativa y la otra desde una perspectiva, si cabe, positiva. En la primera, vemos en la página seis de LaVanguardia del veintisiete de octubre de 1906, como se utiliza de forma negativa respecto a los problemas y descomposición del partido liberal en España en palabras de un miembro: «llevamos en el seno de la comunión el cáncer incurable y homicida, también nosotros vamos caminito de la muerte». La segunda se pudo leer en la página ocho del $A B C$ del veintiséis de septiembre de 1906, en donde se hacía referencia al discurso de Pablo Iglesias en el que explicó «el poderoso incremento del socialismo alemán, al que comparó con un cáncer que corroe las entrañas de la organización burguesa del país germano». 
Asimismo, los periodistas tampoco se libraron de la aplicación del concepto de cáncer desde una perspectiva crítica. En la página cuatro del $A B C$ de veintiocho de enero de 1911, se incluye un artículo con el título Revelaciones Sensacionales, del corresponsal en Londres, en donde se dice: «El Times ha hecho perfectamente en tomar a pecho este asunto y en denunciar este cáncer del periodismo moderno, que no tiene respeto a las leyes ni a la sociedad y que no vela por las hermosas tradiciones del periodismo, que siempre supo mostrarse noble, altivo y generoso».

\section{Discusión}

Las metáforas proporcionan una forma única de percibir y experimentar una importante parte del mundo, pues su capacidad para unir aquello concreto y visual con lo abstracto y complejo proporciona una perspectiva simple a la vez que poderosa, permitiendo en muchos casos la transformación de experiencias, que por sus características podrían ser negativas en positivas o también todo lo contrario.

Tal y como plantean Lakoff y Johnson ${ }^{13}$ «las metáforas no son buenas ni malas, son contextuales, tienen su fuerza y debilidad de manera tal que pueden facilitar la comprensión de la situación a unos o todo lo contrario a otros»; al igual que como Broyard ${ }^{14}$ describió su padecimiento del cáncer, planteando en su descripción autobiográfica que «el hombre enfermo lo contempla todo como una metáfora», puede ser que la sociedad en su conjunto se contemple a sí misma "como una metáfora», en la que coexisten términos negativos y positivos, aquellos que afectan a su definición cultural de bien y mal y ha elegido el cáncer como metáfora. Una metáfora que intensifica las percepciones seleccionadas e ignora otras. Cada metáfora puede ser una forma sutil de poner de manifiesto aquello en lo que se desea creer y evitar aquello que no se desea encarar. ${ }^{15}$

Una parte importante de las investigaciones previas nos sugieren que las metáforas nos proporcionan un encuadre esquemático que guía el proceso cognitivo de aquellos que reciben las metáforas, de las sentencias con-

13 Lakoff, G., Johnson, M., 1981, Metaphors We Live By. Chicago, The University of Chicago Press.

14 Broyard, A., 1992, Intoxicated by my Illness. New York, Fawcett Columbine.

15 Edelman, M., 1971, Politics as symbolic action. Chicago, Marham Publishing Company. 
tenidas de manera literal en la comunicación. ${ }^{16}$ Es común también extender la metáfora del cuerpo enfermo a situaciones de orden político o social, hablar por ejemplo del cáncer que corroe a una sociedad, o a un partido político, o la revuelta que es preciso apagar o reprimir antes de que gangrene a todo el cuerpo social.

El cáncer es una poderosa metáfora, su utilización conduce de manera efectiva a atraer la atención hacia los diferentes y serios problemas sociales. Su correspondiente significado como crecimiento desmesurado y descontrolado la hace idónea para situaciones sociales en las que se produzca un crecimiento desmesurado y pérdida del control. Por lo tanto, no es extraño que deba ser combatido con todas las armas disponibles.

En relación con los artículos analizados se obtuvieron diversas categorías, aunque podría decirse que hay más o menos un principio general de incumplimiento de determinadas convenciones sociales, lo que contribuye al desorden y la falta de organización y, por tanto, ponen en peligro la misma esencia de lo social. En aplicación de lo que dicen Antón y McCourt, ${ }^{17}$ «las metáforas en las rutinas periodísticas de estos escritos tienen la intención de hacer que los temas sean importantes para la audiencia a través de la popularización y dramatización de las temáticas. Los diferentes contenidos temáticos podrían hacernos pensar que se trata de temas distintos, pero independientemente de su contenido, se podría decir que en lo esencial se trata de afirmaciones identitarias y de poder, de la supervivencia de lo social, de la estructura del conjunto, del todo, de una forma de ver el mundo, en un momento concreto, y en donde se perciben elementos o demandas de cambio». Por ejemplo, la defensa de los derechos de la mujer que se realizó en $L a$ Vanguardia del día diecisiete de abril de 1910.

16 Anton, T.y McCourt, R., 1995, The new science journalist. New York, Ballantine Books; Billow, R.M., 1977, «Metaphor: A review of the psychological literature», Psychological Bulletin, 84: 81-92; Mio, J. S., 1993, Responding to metaphors in the context of political debate. 101st Annual Convention of the APA. Toronto, American Psychological Association; Mio, J. S., 1996, «Metaphor, politics, and persuasion». En: J. S. Mio y A. N. Katz, editors. Metaphor: Implications and Applications. Mahwah, NJ, Erlbaum, 127-145; Read, S. J., Cesa, I. L., Jones, D. K., Collins, N. L. 1990, «When is the federal budget like a baby? Metaphor in political rhetoric», Metaphor and Symbolic Activity, 5: 125-149. <https://doi.org/10.1207/s15327868ms0503_1>;Srull, T. K., Wyer, R. S., 1979, «The role of category accessibility in the interpretation of information about persons: Some determinants and implications", fournal of Personality and Social Psychology, 37: 1660-1672. <http://dx.doi.org/10.1037/0022-3514.37.10.1660>

17 Anton, T. y McCourt, R., 1995, The new science journalist. New York, Ballantine Books. 
Otros aspectos que no se pueden olvidar y que están en consonancia con la tradición en nuestro país, son aquellos que tiene que ver con la utilización de elementos religiosos tales como los pecados capitales (avaricia, vanidad, envidia), la expresión de la compasión a través de la identificación de la mendicidad, especialmente la infantil, en definitiva, la pobreza. E inclusive distintos delitos tales como el fraude o la prevaricación, o aspectos relacionados con la cultura y de manera especial con la lectura, que se pide sean sometidos a censura en ánimo de mantener el status quo. Lo que llega a poner en solfa situaciones que se producen en otras latitudes $(A B C$, 28/01/1908), cuestionando las acciones que llevan a cabo otros periodistas. Aspectos todos ellos de afirmación de lo social, aquello considerado como tradicional y de atajar en lo posible aquellas posibilidades de cambio que podrían venir de la mano de la cultura, en especial, de la lectura. Una situación que admite excepciones, no hay que olvidar las quejas y lamentos manifestados en La Vanguardia (17/04/1910), ante la apatía y la falta de iniciativa en términos formativos en el ámbito productivo.

Una consideración específica merece ciertos elementos del momento relativos al patriotismo y el nacionalismo, ya que reflejan como ninguno los aspectos identitarios y de afirmación del poder, encontrando claras referencias a la contraposición de ideas entre el autonomismo y la política española. Mención especial merecen los sucesos de la semana trágica, recogidos por la prensa y en los que se utiliza el cáncer como metáfora, que no solo comportan un significado de oposición del nacionalismo catalán al nacionalismo español, sino que al tiempo comportan la esencia de la lucha de clases. En la base de todos estos problemas estaba una guerra, generando un conflicto social a la vez que problemas económicos para el conjunto del estado (La Vanguardia, 18/02/1912). Una situación que crea indeterminación e inseguridad ante la creación del impuesto al consumo, producida años antes y que, en base a los escritos periodísticos, generaban más mal que bien.

El propio cáncer pudo ser considerado una plaga social, tal y como se anunciaba en el título de la conferencia de apertura del curso académico en la Universidad de Barcelona, y por tanto, algo a combatir, a extirpar, aparentemente en un sentido positivo dado que no conocemos el contenido de la conferencia. Desde hace unas décadas, Sontag ${ }^{18}$ aboga por la no utili-

18 Sontag, S.,1990, Illness as metaphor and aids and its metaphors. New York, Double day Books. 
zación de este tipo de metáforas y plantea que es igualmente erróneo la utilización de la metáfora de cáncer para aspectos negativos en términos sociales, dado que se corre el peligro, en este juego de imágenes, de hacer extensiva esta interpretación negativa a los pacientes afectados de cáncer y los aspectos relacionados con ellos. Las personas con cáncer pueden tener dificultades al escuchar constantemente, en los medios de comunicación, cómo se utiliza el nombre de esta enfermedad para hacer referencia a problemas de tipo social, lo que puede influir para que los pacientes sean percibidos no como simples enfermos, con una enfermedad que podría ser letal, sino que además sean percibidos de una manera vergonzosa.

El paciente con cáncer se convierte en un extraño, alguien que debido a los efectos de enfermedad y tratamiento deviene en ser considerado un extranjero que no puede participar a todos los niveles de las rutinas de la vida diaria. Asimismo, llevar a cabo este tipo de utilización del lenguaje en el que se establece la relación de mal y cáncer, podría tener un efecto negativo en las personas sanas, haciendo del cáncer no solo una enfermedad mortal sino también una enfermedad vergonzosa, que engendra discriminación, segregación, estigma, y un gran ostracismo para el enfermo.

Este tipo de análisis en torno a las imágenes del cáncer nos hace preguntarnos por qué el cáncer más que cualquier otra enfermedad es y plantea situaciones 'horribles'. Una parte de la respuesta podría ser que los mecanismos de producción y progreso del cáncer no son totalmente comprendidos y que, de hecho, en nuestra cultura, aunque las cifras así lo desmienten, cáncer es sinónimo de muerte, en donde paradójicamente la negación de la muerte y su falta de aceptación nos induce a tener un miedo exagerado tanto del cáncer como de la misma muerte.

El cáncer en la actualidad comporta menos estigma que cuando se escribieron, en su tiempo, los artículos analizados en ambos periódicos, pero esto no es óbice para que una parte de la sociedad todavía actúe y/o piense como si los pacientes de cáncer estuvieran contaminados. En términos sociales podríamos decir que no se ha producido ningún cambio, la metáfora es una de las preferidas en todos los ámbitos para referirse a situaciones de corrupción, terrorismo o economía, entre otros.

\section{Conclusiones}

En este estudio hemos tratado de conocer, a través de la prensa, el uso del término cáncer como concepto social, concretamente en dos diarios de 
ideología, aparentemente distinta, el $A B C$ y La Vanguardia, identificando las noticias publicadas sobre ello, así como analizando y comparando los resultados obtenidos. Es decir, hemos tratado de estudiar el uso del término cáncer para la referencia metafórica de determinados procesos identificados con el deterioro de situaciones políticas y sociales.

Aunque el uso de esta metáfora en ambos medios, en conjunto es bastante escaso, su significado queda claro. Se coloca siempre en relación con procesos considerados de descomposición y corrupción, habitualmente en relación con procesos administrativos, políticos y judiciales. Su aplicación está ampliamente extendida dada la permanencia de la idea del cáncer en relación con procesos similares en el organismo humano y por extensión, en el organismo social.

Las metáforas cumplen una función de encuadre, seleccionando determinados aspectos de la realidad percibida y resaltándolos en el texto informativo. Tal y como afirman Lakoff y Johnson, ${ }^{19}$ "mediante su utilización se pueden reflejar y facilitar diferentes formas de dar sentido y evaluación a un tema o experiencia en particular». Algo que podríamos decir se produce en los textos estudiados, a través de las metáforas utilizadas, lo cual nos permite percibir las posibles diferencias en términos ideológicos en ambos medios.

Por ejemplo, en La Vanguardia con motivo de la presencia del rey en la ciudad de Barcelona se procedió a la descalificación de los madrileños; manifestándose también la preocupación por las carencias formativas de los trabajadores, en general, y de las mujeres, en particular, reivindicando las necesidades educativas de éstas y la necesidad de avanzar en el desarrollo de sus derechos. En $A B C$, la mendicidad fue considerada un problema de imagen, explotación de la infancia y alteración del orden, mientras que La Vanguardia lo vinculó a la pobreza.

Los disturbios ocasionados en Barcelona, por la guerra de Marruecos, para el $A B C$ se consideraron falta de patriotismo, relacionando éste con ideas anarquistas y autonomistas, al negarse los ciudadanos a ser reclutados, una situación que en La Vanguardia se abordó desde la preocupación por los costos y su impacto en la economía nacional. No obstante, sí que es posible encontrar puntos en común como, por ejemplo, en relación con la falta de control y fiscalización de los procesos de gasto y de aplicación de las leyes promulgadas, así como de los procesos de corrupción.

19 Lakoff, G., Johnson, M., 1981, MetaphorsWe Live By. Chicago, The University of Chicago Press. 
El cáncer es una enfermedad con un gran impacto en nuestra sociedad. Y la percepción que tenga un individuo del riesgo de padecerlo o de las acciones que pudieran ejercerse para prevenirlo o incluso de la utilización de servicios sanitarios, depende entre otros factores, de la información recibida. De este modo, los mecanismos de prevención serían también aplicables en el ámbito social para prevenir cualquier tipo o proceso de corrupción.

El tratamiento que el subconsciente colectivo asocia con el cáncer ( $\mathrm{ra}-$ dioterapia y quimioterapia) degrada progresivamente al paciente hasta límites insospechados. Lo que hace del cáncer todavía hoy, una poderosa metáfora del rechazo a la decrepitud y del miedo a la muerte y, por tanto, la utilización del cáncer como metáfora de proceso social, es descriptiva, expresa el deseo del cambio, la modificación de una situación para un comienzo renovado, pero no hay que olvidar que su utilización puede comportar situaciones de posible estigmatización de los enfermos afectados por esta patología.

Es por ello, que sería conveniente conocer en profundidad su utilización, en el momento actual, por los medios, y proceder al análisis de su uso realizando un esfuerzo adicional, en su caso, para tratar de comprender cuál es el impacto que puede provocar en las personas afectadas de cáncer.

\section{REFERENCIAS BIBLIOGRÁFICAS}

Antón, Ted y Rick McCourt, 1995, The new science journalist. New York, Ballantine Books.

Berelson, Bernard, 1952, Content analysis in communication research. New York, Free Press.

Billow, R. M., 1977, «Metaphor: A review of the psychological literature», Psychological Bulletin, 84: 81-92.

Broyard, Anatole, 1992, Intoxicated by my Illness. New York, Fawcett Columbine.

Bucchi, Massimiano, 1998, Science and the Media: Alternative Routes in Science Communication. London, Routledge.

Coffey, Amanda y Paul Atrinson, 2003, Encontrar el sentido a los datos cualitativos: estrategias complementarias de investigación. Medellín, Editorial Universidad de Antioquia.

Edelman, Murray, 1971, Politics as symbolic action. Chicago, Marham Publishing Company.

Fiske, John, 1991, «The discourses of TV quiz shows, or school + luck = success + sex». En: Leah R. Vande Berg y Laurence A. Wenner, editors, Television criticism: Approaches and Applications. White Plains, NY, Longman, 445-462. 
Gamson, William A. y André Modigliani, 1989, «Media discourse and public opinion on nuclear power: a constructionist approach». American fournal of Sociology, 95 (1), 1-37. <https://doi.org/10.1086/22921310.1086/229213>

Gibis, Raimon W., 1994, The Poetics of the Mind. Figurative Thought, Language, and Understanding. Cambridge, Cambridge University Press.

Instituto de investigación Rafael Lapesa, 2013, Real Academia Española. Mapa de diccionarios académicos. Disponible en: <http://web.frl.es/ntllet>

Lakoff, George y Mark Johnson, 1981, Metaphors We Live By. Chicago, The University of Chicago Press.

Lakoff, George, 1993, «The Contemporary Theory of Metaphor». En: Orton y Andrew, editors. Metaphor and Thought. Cambridge, Cambridge University Press, 202-251.

Mio, Jeffery S., 1993, Responding to metaphors in the context of political debate. 101st Annual Convention of the APA. Toronto, American Psychological Association.

Mio, Jeffery S., 1996, «Metaphor, politics, and persuasion». En: Jeffery S. Mio y Albert N. Katz, editors, Metaphor: Implications and Applications. Mahwah, NJ, Erlbaum, 127-145.

Moliner, María, 1998, Diccionario de uso del español. Madrid, Gredos.

Read, Stephen J., Ian L. Cesa, David K. Jones, y Nancy L. Collins, 1990, «When is the federal budget like a baby? Metaphor in political rhetoric», Metaphor and Symbolic Activity, 5: 125-149. <https://doi.org/10.1207/s15327868ms0503_1>

SonTANG, Susan, 1990, Illness as metaphor and aids and its metaphors. New York, Double day Books.

SRULL, Thomas K. y Robert S. WYeR, 1979, «The role of category accessibility in the interpretation of information about persons: Some determinants and implications», Fournal of Personality and Social Psychology, 37: 1660-1672. <http:// dx.doi.org/10.1037/0022-3514.37.10.1660> 